\section{La ciencia de Unánue}

\section{Hipólito Unánue, M.D. a Father of Peruvian Medicine and Science}

"Vivimos una sociedad profundamente dependiente de la ciencia, y en la que nadie sabe nada de estos temas, ello constituye una fórmula segura para el desastre."

Carl Sagan 1994

\section{Sr. Editor:}

Hipólito Unánue, Cayetano Heredia, Daniel Alcides Carrión y Manuel Núñez Butrón, representan los símbolos de la medicina peruana, por ello es importante conocer la biografía de estos personajes históricos.

Unánue nació en Arica en 1755, es considerado el padre de la medicina peruana. En la entrada de la Facultad de Medicina San Fernando de la Universidad Nacional Mayor de San Marcos, destaca una imponente estatua de él, por su labor en la fundación de dicha escuela de medicina (Figura 1). Fue un médico que vivió el accidentado tránsito político del Virreinato a la República, fue asesor de los últimos virreyes, entre ellos José Fernando de Abascal, y ministro de dos libertadores: José de San Martín y Simón Bolívar. En enero de 1824, Unánue viajó para atender como médico al Libertador Simón Bolívar, cuando éste se encontraba gravemente enfermo en el refugio militar de Pativilca ${ }^{1}$. Siendo estudiante de medicina, fue testigo en 1780 de la revolución de Túpac Amaru, en Tinta, la que mantuvo en jaque al gobierno colonial español.

La obra política de Unánue y su relación con el poder, se puede resumir así: preocupado por la difusión de la medicina, su profesión, acudió ante el virrey Francisco Gil de Taboada y Lemus y lo comprometió a fundar el Anfiteatro Anatómico, donde médicos y estudiantes comenzaron a practicar la disección de cadáveres; luego, con el virrey Abascal, lo convenció de formar el Colegio de San Fernando, futura facultad de medicina; junto al General José de San Martín firmó el acta de la Independencia del Perú y con el Libertador Simón Bolívar terminó desalojando a los españoles de los Castillos del Real Felipe.

Fue educado por Cosme Bueno, quien había recogido, en 1765, el conocimiento folklórico sobre la teoría unitaria de la bartonellosis por bartonella bacilliformis, y por el doctor Gabriel Moreno a quien dedicó su obra cumbre sobre el clima de Lima. De joven ingresó al seminario para ser sacerdote, pero dejó la religión por la ciencia, ingresando al estudio de la medicina. Aunque su rol como político es objeto de polémica hasta la actualidad, por su rol cómplice en los actos cometidos durante la dictadura de Simón Bolívar en Perú, Hipólito Unánue era un sabio, bajo cualquier punto de vista ${ }^{2}$, la contribución de Unánue en la ciencia está fuera de duda.

Durante los años 1791 a 1794 fue editor del Mercurio Peruano, el vehículo más importante para la difusión de las ideas científicas en Perú, en los albores de la independencia peruana ${ }^{3}$. Los historiadores consideran que Unánue y los jóvenes que se agruparon con él en la revista Mercurio Peruano fueron los fundadores del pensamiento ilustrado en el Perú y a partir de ese pensamiento se diseñó el proyecto de constituir el Perú como una república independiente y moderna.

El sabio naturalista alemán Alexander Von Humboldt afirmó, en relación a la principal obra

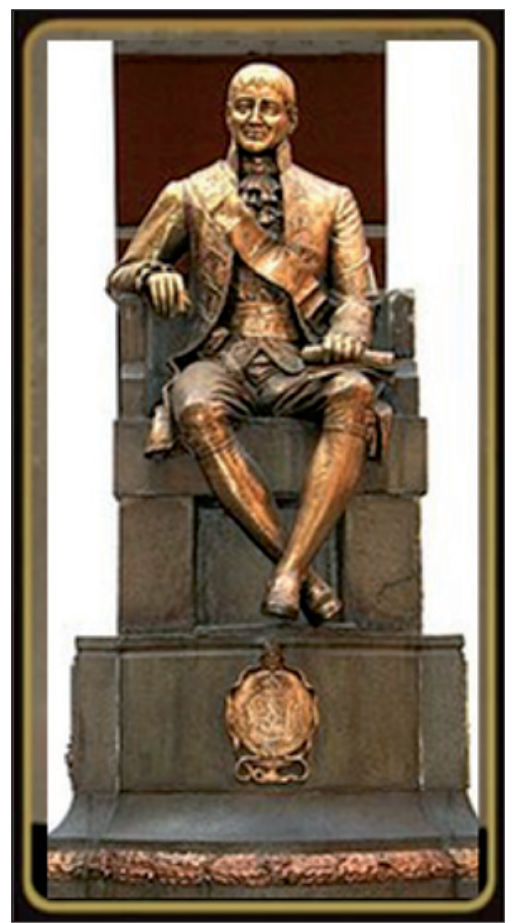

Figura 1. Imponente estatua de Hipólito Unánue a la entrada de la Facultad de Medicina "San Fernando" de la Universidad Nacional Mayor de San Marcos. 
de Unánue publicada en $1805^{3}$, "Observaciones sobre el clima de Lima, y su influencia sobre los seres organizados, en especial el hombre", que era un excelente tratado de fisiología. Este fue el primer libro peruano de medicina, publicado en el extranjero. Aunque Unánue recomendaba los beneficios terapéuticos del clima adecuado, fue muy objetivo en mencionar sus limitaciones como medida terapéutica y mencionaba que "La naturaleza no siempre podía remediar nuestras enfermedades, y entregarlas a solo su poder"'. Enfatizaba la necesidad de aplicar como coadyuvante un remedio específico, en el momento adecuado. Lamentablemente, el concepto de climatoterapia de Unánue fue distorsionado y exagerado en Perú, lo que llevó a que las generaciones futuras de médicos hicieran uso de la naturaleza y el clima como una panacea, llevando por ejemplo a la construcción de sanatorios para pacientes con tuberculosis en algunos valles andinos. Se culpa injustamente a Unánue de una mala influencia en la formación de médicos, que se adhirieron de forma exagerada y dogmática a las propiedades terapéuticas de la naturaleza.

En la actualidad, la climatoterapia definida como un desplazamiento temporal o permanente de una región a otra con clima más favorable, para el manejo de una condición médica, está aceptada científicamente. La climatología médica correctamente aplicada está restringida hasta la actualidad a cuatro patologías: la anemia drepanocítica, la dermatitis atópica, el vitíligo y la psoriasis ${ }^{5}$.

Unánue consideraba que el Estado debía tener a la salud como política de estado. La realización plena del proyecto de desarrollo requería no sólo la comercialización de las riquezas peruanas. Consideraba como causa de la decadencia peruana a la despoblación producida por enfermedades y epidemias. Unánue y sus seguidores fueron consecuentes con sus ideas durante su gestión como autoridades políticas, propiciando sólidas medidas sanitarias como una buena educación médica.

Unánue ejerció su último cargo político como Presidente del Perú, en reemplazo temporal de Simón Bolívar. Luego decidió retirarse de la política a su hacienda en Cañete, Lima, teniendo como vecino ilustre al ex Director Supremo de Chile, Bernardo O’Higgins Riquelme, dueño de la hacienda Montalván que recibió como donación del estado peruano por su importante papel en la independencia del Perú. Años más tarde, el historiador chileno Benjamín Vicuña Mackenna viajó a Cañete para escribir una biografía de ambos. Unánue falleció en 1833, a los 78 años de edad. Sus restos se encuentran en el Panteón de los Próceres de la Nación.

En Perú se ha desarrollado recientemente una polémica por una reciente biografía sobre Unánue ${ }^{6}$, que analiza su papel histórico.

Ciencia es quizás el aspecto más importante y el más determinante del éxito de cualquier sociedad. De ahí la importancia de reconocer el papel científico de Unánue en un momento de la historia del Perú: su constitución como república independiente.

David Salinas Flores

Profesor Invitado de Cátedra de Medicina Interna, Hospital Arzobispo Loayza Universidad Nacional Mayor de San Marcos, Lima, Perú.

\section{Referencias}

1. Polanco T. Crisis en Pativilca en: Simón Bolívar: Ensayo de una interpretación biográfica a través de sus documentos Barcelona. 2000 5ta ed. Prados de la Escoasura L, y Amaral S eds, p. 476-92.

2. Morote H. Bolívar, libertador y enemigo No 1 del Perú. Jaime Campodónico Editor Lima Perú 4ta ed. 2009 p. 139-41.

3. Dager A. Hipólito Unánue en el Mercurio Peruano. Revista de Historia de América, 2001; 128: 97-121.

4. Unánue H. Observaciones sobre el clima de Lima, y su influencia sobre los seres organizados, en especial el hombre. 1815 Madrid. 2da Edición p. 245.

5. Kopel E, Levi A, Harari M, Ruzicka T, Ingber A. Effect of the Dead Sea Climate therapy for psoriasis on quality of life. Isr Med Assoc J. 2013; 15: 99-1.

6. Pamo O. Sobre la magia de Unánue según la magia del doctor Uriel García. Rev Soc Perú Med Interna 2011; 24 : 150.

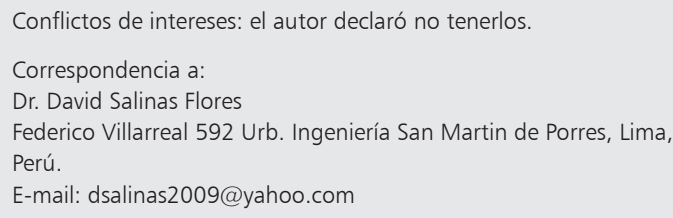

